\title{
Quantum Management of Hospital in the Post-COVID-19
}

\author{
Fahri Özsungur* \\ International Trade and Finance, Mersin University, Turkey \\ *Corresponding author: Fahri Ozsungur, International Trade and Finance, Mersin University, Turkey \\ To Cite This Article: Fahri Özsungur. Quantum Management of Hospital in the Post-COVID-19. Am J Biomed Sci \& Res. 2021 - 14(1). AJBSR. \\ MS.ID.001946. DOI: 10.34297/AJBSR.2021.14.001946.
}

Received: 眥 August 23, 2021; Published: 䟱 August 27, 2021

\begin{abstract}
The aim of this study is to present a management approach to transforming the deficiencies in crisis management during the pandemic period into a strong facet of businesses. In this research, phenomenology and grounded theory were adopted. The results of the study revealed five basic principles in the form of quantum management of hospital management: Infinity of possibilities, resilience to waves of uncertainty and making sense, the complementarity of diversity and complexity, significance of chaos and crisis, interactive outputs. These basic principles are under the influence of three basic factors based on medical, administrative, sharing-interaction.
\end{abstract}

Keywords: Hospital management; Quantum Approach; Quantum Management; COVID-19; Pandemic

\section{Introduction}

COVID-19 has had significant impacts on the healthcare industry [1-4]. The rate of transmission of the virus and the emergence of new variants have adversely affected doctors, nurses, caregivers, doctor's secretaries, and assistant staff in the context of psychology and health [5-6]. In addition to these negative effects, different side effects of vaccines on patients, fluctuations in the decrease and increase in the number of cases necessitated the development of a management method that will provide rapid adaptation to these variable situations in the administrative context of hospitals [7-8]. Hospitals continue to make serious and meaningful efforts to improve doctor-patient, staff-patient relations in their corporate management. Difficulties in implementing the vaccine to individuals in developing countries cause serious difficulties in the management of hospitals [9-10]. Problems in policies related to social security make this situation even more difficult. Trying to turn the negative effects of the pandemic into an opportunity, hackers access confidential information about patients and hospitals through cyberattacks and commit cyber fraud [11-12].

Hospitals, hospital staff, and patients are at risk for their personal data being stolen due to cyber attacks [13]. Hospital managers should identify and implement the necessary strategies in order to eliminate these risks. Cyber attacks can damage the gerontechnological infrastructure of hospitals. These harmful effects may hinder the treatment of the elderly and palliative patients [14-15]. On the other hand, technological devices used in the operating room and patient treatment units can be damaged due to these cyber attacks [16]. Such attacks have been added to the lack of infrastructure that emerged during the COVID-19 era [11-16]. Therefore, crisis management in hospitals has become necessary. The aim of this study is to present a management approach to transforming the deficiencies in crisis management during the pandemic period into a strong facet of businesses. This management approach will bring new principles to the postpandemic management of businesses. The infinity of possibilities, waves of uncertainty, the complementarity of diversity and complexity, the significance of chaos and crisis and interactional outputs of the quantum approach were taken into account in the development of new management principles.

\section{Research Methodology}

In this research, phenomenology and grounded theory were adopted [17-24]. Phenomenology provides to reveal the causes and cause-effect relationships that form the basis of the phenomena 
[17-19]. In this research method, the findings obtained from the interviews are analyzed [17-19]. The phenomenon determined together with the research question is clarified by the analysis of the interview findings [17-19]. The grounded theory consists of pre-sampling, interviews, theoretical memo-writing, theoretical sampling, coding (axial, selective, open coding), quality analysis, illustration of concepts, and constructing/developing theory stages [22-24]. Grounded theory enables the development of existing theories or the creation of a new theory [22-24].

In accordance with the purpose of the research, the research question was determined as follows: What is the new management approach that emerged in Post-COVID-19 Hospital Management? Which management principles benefit patients, doctors, staff, and stakeholders in Post-COVID-19 Hospital Management? After these research questions, interviews were conducted with supervisors, human resources managers, and general managers of 11 hospitals from three provinces (Adana, Mersin, Osmaniye) in order to investigate hospital management. Three participants from each hospital determined by the pre-sampling method were included in the interviews. Interview questions are presented in Table 1. Some of the findings obtained from the conducted interviews required obtaining information from further samples. For this reason, interviews were conducted with 12 managerial personnel of 4 hospitals operating in Antalya and Niğde through theoretical sampling. This was because the emerging heading/ dimension "Complementaryness of difference and complexity" about the quantum approach needed more evidence. In particular, the systemic and individual-based elements of the differences in hospital management were clarified with the theoretical sampling method.

Table 1: Interview Questions.

\begin{tabular}{|c|c|}
\hline Order & Questions \\
\hline 1 & What possibilities have COVID-19 brought in the context of hospital management? What are your solutions to this issue? \\
\hline 2 & What uncertainties has COVID-19 created in the context of hospital management? What strategies have you adopted to eliminate these \\
uncertainties?
\end{tabular}

\section{Ethical Rules and Implication}

In the study, the participants were informed that the participation was carried out on a voluntary basis and that they could end answering the questions of the researcher at every stage of the interview. In addition, the participants were informed about the title, subject, purpose, outputs, limitations, and confidentiality of the study by means of a consent form. The personal data and business titles/brands of the participants were kept confidential. During the coding, all information about the participants and hospitals was anonymized.

\section{Coding Results}

Coding in qualitative research consists of three stages: Open, axial, and selective [25-27]. At these stages, raw data is processed and data is separated with open coding, categories are associated with axial coding, and central and subcategories are revealed with selective coding [25-27]. During the coding in the research, it was determined that the categories were similar to the basic features of quantum philosophy. This determination was supported by theoretical memo-writing (Table 2). The coding results revealed five basic dimensions: Infinity of possibilities, resilience to waves of uncertainty and making sense, the complementarity of diversity and complexity, significance of chaos and crisis, interactive outputs. These dimensions were found to be related to the infinite system, centrifugal force, and fluctuations, twisting properties created by the gravitational force of the Quantum philosophy. For this reason, the findings were associated with the Quantum philosophy.

Table 2: Coding Results.

\begin{tabular}{|c|c|c|}
\hline Dimensions & Sample Expression & Supporting expression \\
\hline Infinity of possibilities & $\begin{array}{c}\text { "COVID-19 has shown us that all possibilities are possible. } \\
\text { Despite the current vaccines and advanced technology, we } \\
\text { learned that we need to take precautions against possible } \\
\text { risks in the treatment of infectious diseases." }\end{array}$ & $\begin{array}{c}\text { "Patients with palliative and upper respiratory problems have } \\
\text { provided endless insights for us to assess the possibilities in the } \\
\text { emergency response complexity posed by COVID-19. We evalua- } \\
\text { ted every possibility in the diagnosis and treatment of diseases." }\end{array}$ \\
\hline $\begin{array}{c}\text { Resilience to waves } \\
\text { of uncertainty and } \\
\text { making sense }\end{array}$ & $\begin{array}{c}\text { "Until uncertainty situations in hospital management are } \\
\text { stable, management responsibility is at risk. Emergency } \\
\text { and intensive care units of hospitals cooperated with } \\
\text { other hospitals in cases of uncertainty." }\end{array}$ & $\begin{array}{c}\text { "Uncertainty in the industry means risk. The number of patients, } \\
\text { disease risk level, technological inadequacies, fluctuations rela- } \\
\text { ted to infection and vaccine depend on the managerial power of } \\
\text { the hospital management to cope with uncertain situations." }\end{array}$ \\
\hline
\end{tabular}




\begin{tabular}{|c|c|c|}
\hline $\begin{array}{l}\text { Complementarity of di- } \\
\text { versity and complexity }\end{array}$ & $\begin{array}{l}\text { "The pandemic has brought up an important problem for } \\
\text { hospitals. This problem is the transformation of the comp- } \\
\text { lexities in the sectors and systems with which we are in } \\
\text { communication into a whole with interaction. The } 99.9 \% \\
\text { probability makes us think of the } 0.01 \% \text { probability. Thus, } \\
\text { both possibilities complement each other." }\end{array}$ & $\begin{array}{l}\text { "We need to focus on the differences emerging in doctor-patient, } \\
\text { hospital-stakeholder relations in the management of hospitals. } \\
\text { Differences are the endless factors that make us who we are, } \\
\text { create our mission, and shape our vision. Cardiology, psychiatry, } \\
\text { gynecology, and all other departments play a complementary } \\
\text { role in the treatment of diseases." }\end{array}$ \\
\hline $\begin{array}{l}\text { The significance of } \\
\text { chaos and crisis }\end{array}$ & $\begin{array}{l}\text { "The pandemic has taught me to cope with difficulties in a } \\
\text { time of crisis. The pandemic has created meaningful awa- } \\
\text { reness on many issues such as the vaccination of patients, } \\
\text { the methods followed in the diagnosis and treatment of } \\
\text { chronic diseases, cooperation with health institutions and } \\
\text { the state." }\end{array}$ & $\begin{array}{l}\text { "COVID } 19 \text { has caused a change and revolution in the manage- } \\
\text { ment approach of our hospital. Patients' respect for healthcare } \\
\text { workers and doctors increased. I can say that the pandemic } \\
\text { provided an important meaning to the individuals who provide } \\
\text { services to the health sector." }\end{array}$ \\
\hline Interactive outputs & $\begin{array}{l}\text { "The collaboration that emerged with the pandemic } \\
\text { created an interaction-based synergy. We interacted for } \\
\text { public health with some companies that we had relations } \\
\text { with due to unfair competition before. This allowed us to } \\
\text { expand our stakeholder network." }\end{array}$ & $\begin{array}{l}\text { "The basic rule in hospital management is to manage instituti- } \\
\text { onal and individual psychology well. This is possible by gaining } \\
\text { positive momentum in interaction with actors such as patients, } \\
\text { personnel, pharmaceutical representatives, companies selling } \\
\text { medical drugs, tax offices, professional organizations, non-gover- } \\
\text { nmental organizations with whom we are in contact." }\end{array}$ \\
\hline
\end{tabular}

\section{Theoretical Memo-Writing}

Theoretical memo writing has an important function in revealing the theoretical structure [28-29]. This method is applied to determine whether the data obtained is sufficient for the development or construction of a theory and whether more evidence is needed [30]. In order to obtain more information about the strategy applied against the waves of the uncertainty of the pandemic in the questions asked to the hospital operators, interviews were conducted with 12 managers of 4 hospitals operating in Antalya and Niğde by means of theoretical sampling.

\section{Quantum Management in Hospital}

Findings and coding analysis results showed that three basic factors of hospital management based on medical, administrative, sharing-interaction are effective in the management approach caused by the pandemic. The results of the analysis of the data obtained from the participants revealed that the main reasons for the five factors of the Quantum philosophy (Figure1) revealed by this research are medical, administrative, sharing-interaction.

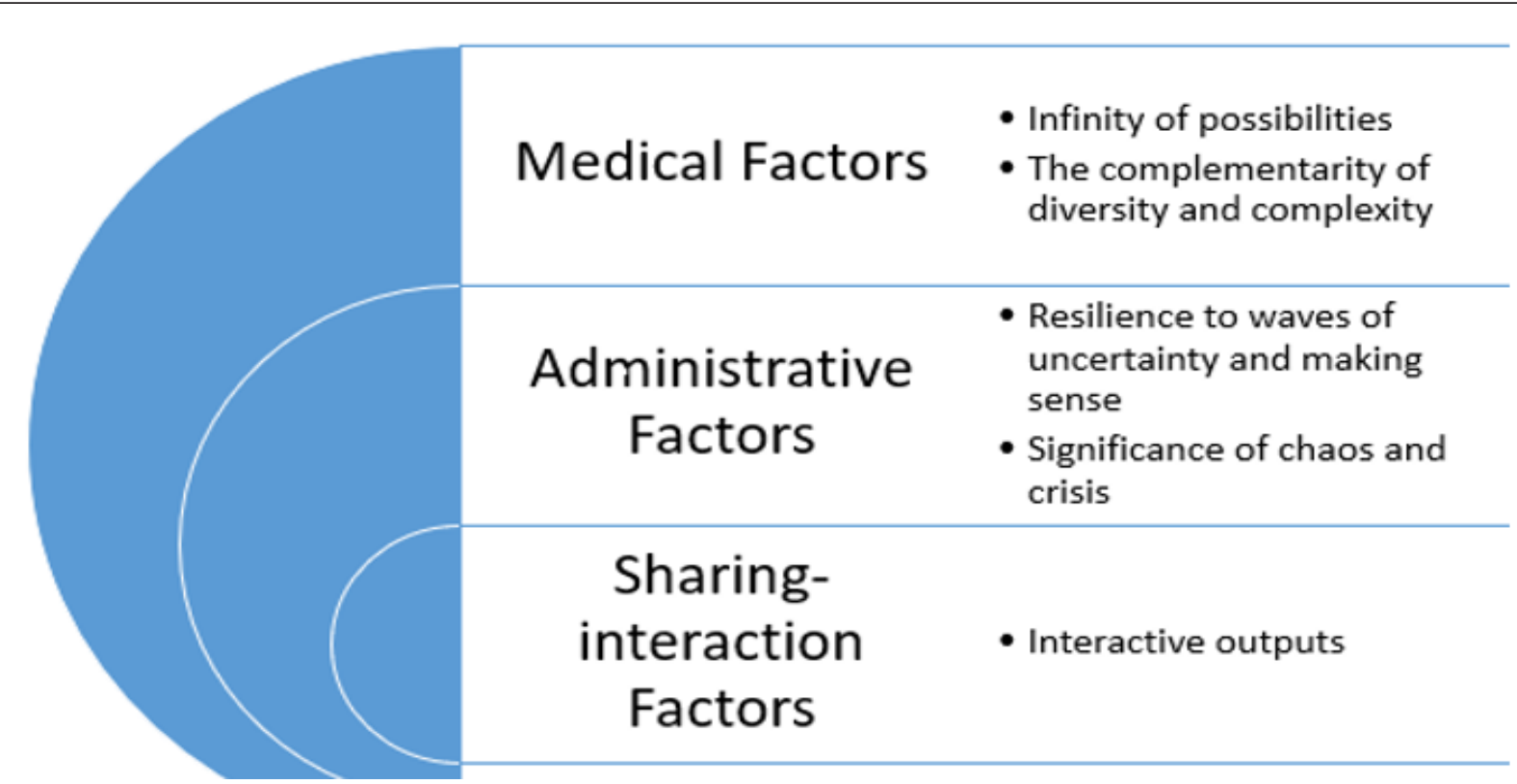

Figure 1: Management factors in quantum hospital management.

\section{a) Medical Factors}

The medical factor consists of diseases, sanitation in-hospital services, diagnosis-treatment methods, professional competence of doctors and staff, technological and technical infrastructure, and Research \& Development sub-factors. Medical factors have important functions in the fight against diseases of hospital management.

b) Administrative Factor

Administrative factors are related to the efficient management of the hospital. The findings revealed that the strategic, crisis- 
based management of hospital management is important for eliminating potential risks. According to the information obtained from the participants, administrative factors consist of human resources, procurement, law, teamwork, mentoring, and training sub-factors. The training was reported by the participants as an activity that should be carried out continuously and together with the stakeholders.

\section{c) Sharing-Interaction Factors}

Hospital management can create synergy by interacting with actors such as stakeholders, patients, doctors, staff, government, non-governmental organizations, universities, tourism companies. The findings showed that the communication, interaction, and sharing with these actors should be increased in order for hospitals to operate in accordance with their establishment purposes, customer satisfaction, and realization of their visions. Especially during the pandemic period, cooperation and interaction with actors such as public institutions and organizations, nongovernmental organizations, companies have provided important developments in the fight against COVID-19. Participants predicted that investment in human health, which was more important than business profitability, would provide significant benefits and outputs in the future.

\section{Conclusion and Discussion}

COVID-19 has caused critical changes in organizational behavior, organizational psychology, business strategies, and management understanding. The results of the study revealed five basic principles in the form of quantum management of hospital management: Infinity of possibilities, resilience to waves of uncertainty and making sense, the complementarity of diversity and complexity, significance of chaos and crisis, interactive outputs. These basic principles are under the influence of three basic factors based on medical, administrative, sharing-interaction. The infinity of possibilities represents the numerical equivalent of the odds of medical risks and threats, from 0 to 1 , in the face of COVID-19 and the virus threat that has changed over the centuries. Despite technological, gerontechnological, digital, and technical innovations, health problems that may arise in the medical field affect humanity and hospital management. This infinity should be taken into account by doctors, health workers, and administrative personnel in business management. When these possibilities are determined in advance after the pandemic, the strategy and management approach to be adopted in similar situations that may arise in the future can be easily determined. Resilience to waves of uncertainty and making sense symbolize the management policy and struggling spirit that the hospital management will adopt against extraordinary situations such as pandemics. In these cases, fluctuations related to the number of patients, disease risk level, technological inadequacies, infrastructure deficiencies, infection, and vaccine should be determined beforehand. Procurement strength and network, stakeholders, location in the supply chain, and hospital-related commitments of staff are important factors in this resilience and coping power. The complementarity of diversity and complexity represents the hierarchical form of structuring in hospital management, the opposing possibility of every possibility. Differences in personnel, medical, hierarchical structure, specialties, and departments complement and support each other. For instance, the cardiology service complements and supports the gynecology department, the gastroenterology department the pediatric department, and its patients.The significance of chaos and crisis is that all units of the hospital act in cooperation as a whole. Crises are a reason for gaining strength in hospital management. The hospital gains experience and a struggling spirit in the face of any harmful situation that arises. Therefore, crisis and chaos can be turned into opportunities as strong strategies. Interactive outputs represent collaborations that have emerged with the pandemic. The interaction with actors such as patients, staff, pharmaceutical representatives, companies selling medical drugs, tax offices, professional organizations, non-governmental organizations increased with the pandemic. This situation enabled hospitals to become stronger, to increase their sustainability and competitiveness. As a result, the Quantum hospital management approach created by this study revealed the principles that they can adopt in the treatment of infectious diseases, pandemics, and extraordinary situations. These principles provide important insights and inspiration about which principles hospitals should adopt in the administrative context in the other possible pandemics. The fact that the study was carried out with a small number of samples affected the generalizability of the results. For this reason, it is recommended that future studies be carried out with samples with different cultural characteristics.

\section{References}

1. Javaid M, Haleem A, Vaishya R, Bahl S, Suman R, et al. (2020) Industry 4.0 technologies and their applications in fighting COVID-19 pandemic. Diabetes \& Metabolic Syndrome: Clinical Research \& Reviews 14(4): 419-422.

2. Foster J, Hodder SG, Goodwin J, Havenith G (2020) Occupational heat stress and practical cooling solutions for healthcare and industry workers during the COVID-19 pandemic. Annals of work exposures and health 64(9): 915-922.

3. Muthuppalaniappan M, Stevenson K (2021) Healthcare cyber-attacks and the COVID-19 pandemic: an urgent threat to global health. International Journal for Quality in Health Care 33(1): 117.

4. Haleem A, Javaid M, Vaishya R, Vaish A (2020) Effects of COVID-19 pandemic in the field of orthopaedics. Journal of Clinical Orthopaedics \& Trauma 11(3): 498-499.

5. Maben J, Bridges J (2020) Covid-19: Supporting nurses' psychological and mental health. Journal of clinical nursing, Accepted-Article.

6. Galbraith N, Boyda D, McFeeters D, Hassan T (2021) The mental health of doctors during the COVID-19 pandemic. BJPsych bulletin 45(2): 93-97.

7. Cao Y, Li Q, Chen J, Guo X, Miao C, et al. (2020) Hospital emergency management plan during the COVID-19 epidemic. Academic Emergency Medicine 27(4): 309-311. 
8. Hermans C, Lambert C, Sogorb A, Wittebole X, Belkhir L, et al. (2020) In-hospital management of persons with haemophilia and COVID-19: practical guidance. Haemophilia 26(5): 768-772.

9. Marini JJ, Gattinoni L (2020) Management of COVID-19 respiratory distress. Jama 323(22): 2329-2330.

10. Flemming S, Hankir M, Ernestus RI, Seyfried F, Germer CT, et al. (2020) Surgery in times of COVID-19-recommendations for hospital and patient management. Langenbeck's archives of surgery 405(3): 359-364.

11. Lallie HS, Shepherd LA, Nurse JR, Erola A, Epiphaniou G, et al. (2021) Cyber security in the age of covid-19: A timeline and analysis of cybercrime and cyber-attacks during the pandemic. Computers \& Security 105:102248.

12. Okereafor K, Adelaiye O (2020) Randomized cyber attack simulation model: a cybersecurity mitigation proposal for post covid-19 digital era. International Journal of Recent Engineering Research and Development (IJRERD) 5(07): 61-72.

13. Almeida BDA, Doneda D, Ichihara MY, Barral-Netto M, Matta GC, et al. (2020) Personal data usage and privacy considerations in the COVID-19 global pandemic. Ciência \& Saúde Coletiva 25(1): 2487-2492.

14. Fusi-Schmidhauser T, Preston NJ, Keller N, Gamondi C (2020) Conservative management of Covid-19 patients emergency palliative care in action. Journal of pain and symptom management, 60(1): 27-30.

15. Li P, Chen L, Liu Z, Pan J, Zhou D, et al. (2020) Clinical features and shortterm outcomes of elderly patients with COVID-19. International Journal of Infectious Diseases 97: 245-250.

16. Pranggono B, Arabo A (2021) COVID-19 pandemic cybersecurity issues. Internet Technology Letters 4(2): 247.

17. Giorgi A, Giorgi B (2003) Phenomenology. Sage Publications, Inc.
18. Moran D (2002) Introduction to phenomenology. Routledge.

19. Sokolowski R (2000) Introduction to phenomenology. Cambridge university press.

20. Strauss A, Corbin JM (1997) Grounded theory in practice. Sage.

21. Charmaz K (2014) Constructing grounded theory. sage.

22. Dey I (2004) Grounded theory. Qualitative research practice 80-93.

23. Oktay JS (2012) Grounded theory. Oxford University Press.

24. Charmaz K, Smith J (2003) Grounded theory. Qualitative psychology: A practical guide to research methods $2: 81-110$.

25. Moghaddam A (2006) Coding issues in grounded theory. Issues in educational research 16(1): 52-66

26. Williams M, Moser T (2019) The art of coding and thematic exploration in qualitative research. International Management Review 15(1): 45-55.

27. Kendall J (1999) Axial coding and the grounded theory controversy. Western journal of nursing research 21(6): 743-757.

28. Lempert LB (2007) Asking questions of the data: Memo writing in the grounded. The Sage handbook of grounded theory 245-264.

29. Lee D, McAlister A, Ehlert K, Faber C, Kajfez R, et al. (2019) Enhancing research quality through analytical memo writing in a mixed methods grounded theory study implemented by a multi-institution research team. In 2019 IEEE Frontiers in Education Conference (FIE) pp. 1-7: IEEE.

30. Engward H (2013) Understanding grounded theory. Nursing Standard 28(7): 37 . 